Please do not remove this page

RMIT

UNIVERSITY

\title{
Preparing students for university studies and beyond: a micro-credential trial that delivers academic integrity awareness
}

Ruddy, Christine; Ponte, Frank

https://researchrepository.rmit.edu.au/esploro/outputs/9921863471501341/filesAndLinks?institution=61RMIT_INST\&index=null

Ruddy, C., \& Ponte, F. (2019). Preparing students for university studies and beyond: a micro-credential trial that delivers academic integrity awareness. Journal of the Australian Library and Information Association, 68(1), 56-67. https://doi.org/10.1080/24750158.2018.1562520

Document Version: Accepted Manuscript

Published Version: https://doi.org/10.1080/24750158.2018.1562520

Repository homepage: https://researchrepository.rmit.edu.au

(C) 2019 Christine Ruddy and Frank Ponte

Downloaded On 2023/04/26 15:54:04 +1000 
Thank you for downloading this document from the RMIT Research Repository.

The RMIT Research Repository is an open access database showcasing the research outputs of RMIT University researchers.

RMIT Research Repository: http://researchbank.rmit.edu.au/

\section{Citation:}

Ruddy, C and Ponte, F 2019, 'Preparing students for university studies and beyond: a micro-credential trial that delivers academic integrity awareness', Journal of the Australian Library and Information Association, vol. 68, no. 1, pp. 56-67.

See this record in the RMIT Research Repository at:

https://researchbank.rmit.edu.au/view/rmit:53423

Version: Accepted Manuscript

Copyright Statement:

(C) 2019 Christine Ruddy and Frank Ponte

\section{Link to Published Version:}

https://dx.doi.org/10.1080/24750158.2018.1562520 


\section{Journal of the Australian Library and Information Association Preparing students for University studies and beyond: A micro-credential trial that delivers Academic integrity awareness \\ --Manuscript Draft--}

\begin{tabular}{|l|l|}
\hline Full Title: & $\begin{array}{l}\text { Preparing students for University studies and beyond: A micro-credential trial that } \\
\text { delivers Academic integrity awareness }\end{array}$ \\
\hline Manuscript Number: & UALJ-2018-0038R2 \\
\hline Article Type: & Peer reviewed research-in-practice \\
\hline Keywords: & micro-credential; digital badge; library instruction; academic integrity; digital literacy \\
\hline Abstract: & $\begin{array}{l}\text { Microcredentials are making an impact on University course curriculums. Increasingly } \\
\text { industry partners have indicated that students exit university with negligible "soft skills" } \\
\text { such as, team work, leadership, and digital literacy skills. Micro-credentials are now } \\
\text { being viewed favourably as a platform to address this deficit in workplace skills. } \\
\text { Universities are now expending considerable time identifying industry skill gaps to } \\
\text { provide students with the attributes that will serve for a successful transition to the } \\
\text { world of work. This paper addresses the development of an academic integrity } \\
\text { awareness micro-credential for new student entrants to university. The trial of this } \\
\text { micro-credential provides students with foundational skills in understanding the } \\
\text { academic world, subsequently providing the advantage required for a successful } \\
\text { transition to industry. }\end{array}$ \\
\hline
\end{tabular}


Preparing students for University studies and beyond: A micro-credential trial that delivers Academic integrity awareness

Research in practice paper (4173 Words)

Christine Ruddya and Frank Ponte

aLibrary and Student Success, RMIT University, Melbourne, Australia; Library and Student

Success, RMIT University, Melbourne, Australia

\section{Christine Ruddy}

Email: Christine.ruddy@rmit.edu.au

ORCID: https://orcid.org/0000-0003-0746-3908

Linkedln public profile: https://www.linkedin.com/in/christine-ruddy-76773a101/

Christine Ruddy is a Reference Librarian at RMIT University Library and supports liaison for the

School of Management within the College of Business. Christine has a keen interest in

information and digital literacies. Christine is currently working on library-supported modules for the RMIT Creds program.

\section{Frank Ponte (AALIA CP)}

\section{Email: Frank.ponte@rmit.edu.au}

ORCID: https://orcid.org/0000-0001-5345-1225

Twitter - https://twitter.com/ponte frank

Linkedln public profile: https://au.linkedin.com/in/francoponte

Frank Ponte is the Manager Liaison for College of Science Engineering and Health at RMIT University Library. Frank is responsible for liaison activities with the academic staff of the college and also leading and managing Liaison Librarians that support students and staff within each school of the College. Frank's other responsibilities include digital learning, the introduction of open educational resources to staff, and facilitating liaison activities which support the introduction of the new learning management system in 2018. 


\title{
Preparing students for University studies and beyond: A micro-credential trial that delivers Academic integrity awareness
}

\begin{abstract}
Micro-credentials are making an impact on University course curriculums. Increasingly industry partners have indicated that students exit university with inadequate "soft skills" such as, team work, leadership, and digital literacy skills. Micro-credentials are now being viewed favourably as a platform to address this deficit in workplace skills. Universities are now expending considerable time identifying industry skill gaps to provide students with the attributes that will serve for a successful transition to the world of work. This paper addresses the development of an academic integrity awareness micro-credential for new student entrants to university. The trial of this micro-credential provides students with foundational skills in understanding the academic world, subsequently providing the advantage required for a successful transition to industry.
\end{abstract}

Keywords: micro-credential, digital badge, library instruction, academic integrity, digital literacy

\section{Introduction}

Royal Melbourne Institute of Technology University (RMIT) is a multi-campus university based in Melbourne, Australia, offering higher education degrees and vocational training. In seeking to strengthen and enhance the delivery of instruction in academic integrity and referencing RMIT University Library, in collaboration with the RMIT Creds Team, developed a micro-credentialled course. This short, online course was intended to improve students' awareness of academic integrity and plagiarism, and practice in undertaking referencing and citation. The course was trialled with first-year nursing students in May 2017 and has subsequently been implemented as part of a broader suite of training offered through the RMIT Creds program. The RMIT micro-credentials program reflects a growing trend in the higher education sector to capitalise on digital avenues to provide more training and greater flexibility to students. The digital badges which certify the completion of a cred, reflect RMIT's desire 
to enhance students' work skills and employability, many of which align with the university's graduate competencies. In providing training in transferable and cross-disciplinary skills like digital literacy, libraries may be the real drivers and contribute to the success of a Creds program.

Micro credentials are short courses generally available online, completed by students in their own time. They incorporate elements of student-centred, collaborative and interactive learning. A digital badge is the certification and acknowledgement of the completion of a micro-cred, which is transferable across digital environments, including LinkedIn and social media and in the case of university-issued badges, can also be attached to a student's academic transcript.

Digital badges were first seen in gaming (McIlvenny, 2015) and the idea of recognising online learning for education or professional development soon spread with the development of open credentials. Open badges are open source symbols of accomplishment with standardised specifications and shared metadata that are recognised across different platforms and organisations (Devedžic and Jovanovic, 2015). The Mozilla Foundation's Open Badges program, established in 2011, enabled widespread adoption of digital badges by business, education and industry. Other badging systems are used, including by MOOC providers such as Udemy and the Khan Academy (Ahn, Pellicone, \& Butler, 2014; Randall, Harrison, \& West, 2013)

Micro-credentials and digital badging have continued to gain traction and popularity. In 2018 the Gartner research company declared 'Digital Credentials' to be the top trend in strategic technologies impacting higher education. In 2017, the top trend was listed as 'Open Credentials' and in 2016, Open Micro-credentials were considered the $5^{\text {th }}$ most important 
strategic technology (Jan-Martin Lowendahl, Thayer, \& Morgan, 2016; JanMartin Lowendahl, Thayer, \& Morgan, 2016; Lowendahl et al., 2018).

The emergence of open digital badges may have been viewed as disrupting the higher education sector. However, this potential 'David and Goliath' story has been upended as 'universities, can, of course, become badge issuers' (Wilson et al 2016), and indeed many have including many prominent educational institutions such as MIT, Purdue, Seton Hall, Yale, Carnegie Mellon, and the ANU (Abramovich, Schunn, \& Higashi, 2013; Diaz, 2013; Rutherford, Freund, \& Mewburn, 2015). Badges may be created and managed by universities, or universities may adopt proprietary badging systems like Credly or TrueCred. Proprietary badging operates similarly to open badges in the higher education context but have greater flexibility to suit their environment. For example, they can incorporate a scaffolding approach to learning, include relevant assessment and more closely align their micro-credentials with graduate outcomes. They can also "provide a form of alternative assessment which supports collaboration and engagement" (Carey and Stefaniak, 2018). RMIT's use of the Credly platform means badges can be customised to RMIT's micro-credentials, whilst also allowing portability.

Micro-credentials cater to a growing demand for skills development external to curricula, work relevant skills, and for self-directed and flexible learning, (Dowling-Hetherington and Glowatz, 2017). The micro-credentialled courses offered at RMIT are designed to increase students' skills and allow for 'upskilling and reskilling'. RMIT aims to provide soft skills that are 'sought within organisations' (Sara Caplin cited in RMIT Creds, 2018) and align with the institute's graduate attributes. These include life-long learning and cultural awareness, but also transferable digital skills and more granular or specialised skills for certain occupations or industries. RMIT creds are developed in partnership with various industry partners to 
appropriately target and develop these skills. To deliver the digital credentials to students, RMIT uses the Credly digital badging site. Credly is a platform that allows individuals to claim their digital badges and demonstrate their achievements through social channels like LinkedIn.

Some academic libraries recognise the value of developing micro-credential courses as an avenue for their instruction and training. In addition to training students micro-credentialled courses allow academic libraries to demonstrate their expertise in information literacy (IL), digital literacy and other library related competencies. These skills are valuable to students academically, but also for their employment prospects and lifelong learning. Libraries have struggled to foster long-term legitimacy for their training, and face obstacles in implementing consistent and systematic training, usually resorting to the 'one shot' or informal delivery of information instruction (Raish and Rimland, 2016; Rodgers and Puterbaugh, 2017). This means that information literacy and other library-based training has not been fully developed, targeted, nor recognised as a legitimate or valid academic pursuit within universities.

This paper looks at the trial of the first micro-cred at RMIT, the Academic Integrity Awareness course. It has now become part of a wide portfolio of micro-cred courses on offer to students. The RMIT Creds program is an institution-wide approach to equipping students with valuable skills and rewarding them for their accomplishments, and courses like academic integrity and information literacy are part of this growing suite of offerings. Programs like RMIT Creds provide an institutionally recognised platform and framework for library-developed courses, add legitimacy to the training, and can act as an incentive and motivation for students (Ahn, et al., 2014; Foli, Karagory, \& Kirby, 2016). 


\section{Literature review}

Universities have had to change, adapt and update with prevailing technologies, pedagogical influences and institutional imperatives. What is crucial is the need to design and deliver content online in a flexible and accessible format that caters to the demands and habits of today's learners: to provide '21st-century learning that is networked, self-directed, projectbased, and personalized' (Hickey, 2017, p. 2). Equally, the higher education sector must innovate to provide skills that meet workplace and industry requirements (Lewis and Lodge, 2016, p. 41). Universities will 'no longer instruct students predominantly on content, but also on news literacy, written and oral communication and career-specific skills and techniques, and provide networking and knowledge advancement opportunities' (Wolfe and Andrews, 2014, p. 210). Universities have been challenged with the emergence of MOOCs (LeónUrrutia, Cobos, \& Dickens; O'Connor, 2014a) and more digital channels to provide education more flexibly and to a wider audience and some consider traditional system of teaching and the awarding of degrees to be out-dated or even 'the result of an older, more naive world' (de Botton, 2015). This certainly has implications for teaching and learning within universities and micro-credentials are one way in which universities are responding to the way learning is evolving and expanding beyond the classroom

\section{Micro-credentials in the academic space}

Micro-credentials are another step in the reorientation of universities toward digital spaces and delivery of student-centred learning (O'Connor, 2014b). Students already have the opportunity to build skills and knowledge external to curricula, whether through volunteering, mentoring, student activities, or the informal accumulation or strengthening of certain skills. Universities are also well placed to accredit such activities, as well as to exploit the continued growth in online learning and learning in social networks (Wilson, Gasell, Ozyer, \& Scrogan, 2016). Micro-credentialed courses allow for the formalising, recognition and verification of the 
informal accumulation of skills and knowledge gained alongside formal learning (Diaz, 2013). Technologies in higher education also support creds. Furthermore, the reputation and credibility of universities means that any micro-credentials will more likely be supported and enjoy competitive advantage (Wilson, et al., 2016).

The continued interest in and promotion of micro-credentials is demonstrated by the Educause online community. It is an instructive and collaborative site for those already involved in or seeking to adopt micro-credentialling and associated badging systems (Educause, 2018).

While debate continues around the role of universities and the extent and type of vocational training they should deliver, there is nonetheless a continuing focus and an imperative to provide students with more evidence of industry and workplace skills via graduate attributes (overarching capabilities) and experience via a variety of methods. Indeed, this shift to a more vocational focus within universities supports the development of micro-credentials (Lewis and Lodge, 2016). RMIT is at the forefront of this with an emphasis on providing industry connections and experience, including through its "Ready for Life" and "Work strategy" and "Work Integrated Learning" (WIL) programs. Underpinning, and aligning with, these programs and graduate attributes, are competencies in information and digital literacies. Digital literacies will no longer be a supplemental skill in the workplace, but a necessary and advantageous one (ECDL Foundation, 2014). Micro-creds created by libraries can form a part of the developing skill-set for students entering employment.

\section{Micro-credentials and workplace skills}

There is increasing need of more specialised skills, including information and digital literacies, as well as more generic competencies including critical thinking and teamwork, that are identified as part of RMIT's graduate attributes. Meanwhile, strength in meta-literacies, 
including the ability to communicate and think critically across digital contexts, is also being recognised by employers (Raish and Rimland, 2016) and constitutes some digital offerings available (Affinito, Forte, Gardner-Athey, Jacobson, \& O'Brien, 2017). This exemplifies the continuing change and shift in learning and teaching amongst the ever-growing ubiquity of the digital. Micro-credentials address a need to not only offer training in these areas, but evidence of what has been learnt, and signifies enthusiasm to learn beyond the formal curriculum. Universities have the resources and leverage to provide this extra learning and are: 'in a unique place to create a meaningful system of certification that reveals information to potential employers through badging' (Wolfe and Andrews, 2014, p. 213).

The acquisition of additional and co-curricular skills is advantageous in an increasingly competitive job market where more industry specific skills are sought after and may even be required. The rate of change with technology means that students may no longer be able to place confidence in what is only learnt through a degree but may instead need to update and improve upon what they already know (ECDL Foundation, 2014). More skills, demonstrating learning at more granular and specialised levels will give employers greater insight into their learning and employers will “... value workers who have amassed collections of specific skills, not those with name-brand diplomas" (de Botton, 2015).

It is important to stress that micro-credentials must be valued by employers instead of being created on assumed knowledge of industry requirements. Research shows that so far there has been minimal adoption by human resources departments but there is some recognition by software and manufacturing firms (Catalano and Doucet, 2013) while many organisations are accepting badges created on through open badging platforms (Raish and Rimland, 2016). There is however a noted concern by employers, particularly when it comes to the information literacy skills of incoming graduates (Raish and Rimland, 2016). In developing 
badges for information or meta-literacies or anything else, it is essential that industry is involved to determine the skills gaps that can be addressed through micro-credentials.

Whilst the main attraction of digital badges for students is the opportunity to build a portfolio of skills that are valued by employers, they are also useful tools for universities to engage and motivate their students through a dynamic and student-centred model of learning (Ahn, et al., 2014). As micro-creds and digital badges continue to grow, and may still be in their nascent phase, evidence suggests that they are a successful means of motivating and engaging students to build their skills (Briggs, 2013; Shields and Chugh, 2017, p. 1823). Motivating students is particularly useful for library-related courses. Often voluntary, external to curricula, or provided on one-shot basis (Mery, Newby, \& Peng, 2012), library instruction in information literacy may establish itself as a more valid and essential training.

\section{Libraries and micro-credentials}

Whilst micro-credentials have been taken up by many universities, only recently emerging literature suggests an uptake by libraries, despite their 'natural fit' (Rutherford, et al., 2015). Libraries offer skills and training for a range of academic and digital competencies and have been successfully navigating new online environments and acting as an intermediary between digital technologies and online content and its users, for some time. With the proliferation and pervasiveness of digital content and technologies, it's been necessary for libraries take on this 'important role in developing training to provide greater access and fluency in digital research skills and training' (Rutherford, et al., 2015). Librarians have instructed in digital and information literacies, either by contributing to a student's academic performance, or to a client's lifelong learning, for many years. 
In the academic context, library instruction that includes information and digital literacies have potential application in the workplace and for lifelong learning. These competencies are usually already taught alongside students' study program or are available online to students to undertake voluntarily, rather than being integrated into the curriculum or compulsory. It has often been a struggle for libraries within universities to establish programs in information literacy and to achieve a sense of validity and legitimacy for these programs across the institution and amongst students. Micro-credentialing library instruction is an opportunity to create a perception of value around library training. More university libraries are now adopting micro-credentials.

The Australian National University library was prompted to transform its online programs for information and digital literacy skills for micro-credentials and badging after an overseas student requested certification of library skills learnt for any overseas employer (Rutherford, et al., 2015). It subsequently developed the Insignia program, which was designed for research students to develop 'key transferable skills in digital and information literacies'. Badges awarded at certain points during students' research provided a useful means to mark or 'anchor' their learning at various points and complexity. The ANU library has provided a valuable example of the way a program can be developed using library resources which are attuned to student needs.

In the US, Warner College developed a micro-credentialled course for information literacy (IL) as the existing model of instruction was deemed inadequate. Whilst there was IL instruction informally embedded within the curriculum, there was no means of assessing students' baseline competency. This was important as information literacy was considered crucial in fulfilling the university's GE (General Education similar to graduate attributes) outcome of 'critical reasoning'. Despite the expected technical issues and necessary efforts to raise awareness of 
the badges, the library had felt that the overall success of the program had left them 'with the notion that digital badges and micro-credentials are here to stay' (Rodgers and Puterbaugh, 2017, p. 8).

Like Warner College, more universities, including RMIT, are looking at embedding microcredentials within the broader LMS framework as the next step. The embedding of Librarybased micro-credentials into the LMS can increase participation and engagement. One case study is Auckland University, who with Future Learn developed a MOOC in information literacy that has been successful in increasing student engagement with the topic (Cook, Bingham, Reid, \& Wang, 2015).

RMIT Library already maintains and creates a large volume of training content and resources, much of it suitable for micro-credentials. The training that is currently delivered however is currently decentralised, fragmented and inconsistent. By developing content for microcredentialled courses, it is possible that a more cohesive and centralised approach to library instruction will be developed. Considering the trial of the academic integrity micro-cred, this paper will examine the outlook for further courses that can be offered by the RMIT University Library to properly integrate and formalise library training.

\section{Background to the Academic Integrity micro-credential trial}

Due to staffing changes and structural re-alignments at the University, the Library was nominated custodian of Academic Integrity. Previously the library saw itself as a supporter of academic integrity by the promotion of, and training in, referencing skills. However, custodianship now meant it was tasked with offering a comprehensive and appropriate program for training for all students across all elements of academic integrity.

Considering these changes, a broader strategy was required to support academic integrity at 
RMIT. The ultimate development of the academic integrity module arose from questions and discussions about how RMIT Library might improve its academic integrity instruction. The discussion surrounding new academic integrity training was driven by the new Deputy Vice Chancellor Education (DVCE), who examined current instruction and found it far too diffuse. In discussions about improving instruction, the DVCE asked participants to 'think outside the box', away from traditional and conventional forms of delivery. In devising a new mode of delivery, it was considered important to factor in the student cohort's styles and preferences for learning, and how this might influence the module's development.

To address how the Library would support academic integrity at RMIT University, as well as the educational standards set out in the Higher Education Standards Framework (Threshold Standards) 2015, a commercial product was initially investigated and demonstrated to staff. It was hoped that this product would address the academic integrity requirements for students. While the product had considerable and credible content, it was perceived as far too linear, not localised, excessively long and therefore was not adopted.

A MOOC style offering that students would complete upon acceptance to RMIT was considered but dismissed as it required significant University financial and infrastructure support. The intent behind the MOOC was to provide incoming first-year students with key information, as well as a digital credential that could be shared on social media and appended to their academic transcript. While the idea has not been pursued at this stage, it is still regarded favourably as an opportunity for further development.

Instead, the Library selected a microlearning app, EdApp, to develop a mobile friendly trial demonstration course on Academic Integrity. The selection was made on the basis it was free 
(with some limitation on storage), provided active learning, gamification, and the flexibility to deliver personalised learning to individuals, anywhere, anytime. The academic integrity demonstration course contained a set of modules, and, was subsequently utilized as a tool to demonstrate what could be developed to selected staff. The development of this course provided the impetus for discussions with the now formed 21 st century skills credentialing project (21CC) group at RMIT. This team has since renamed itself RMIT Creds.

The Library and Student Success team was one of the first groups asked to contribute a module on Academic Integrity based on the development work that it had done with EdApp.

The RMIT Creds team tasked the Library and Student Success team with developing the content and module over an eight-week period to be delivered in the new learning management system, Canvas. The self-registering module was launched in February of 2017 and trialled with an undergraduate cohort in April/May of 2017.

\section{Academic integrity micro-credential trial}

The library's first micro-credential began with the trial of the Academic Integrity Awareness course for nursing students in May 2017. This first year Bachelor of Nursing cohort of 200 students was identified as an appropriate group to target, and viewed as a means to engage students as part of RMIT's “1st 60 days" program. The 1st 60 days program encourages students to become part of the RMIT community, by connecting with clubs, collectives, arts, culture, trips and tours. It is also an essential way to ensure that students begin to feel confident academically and knowledgeable of the various support services available to them.

The Academic Integrity course offers students an entryway into library instruction, and a straightforward and unthreatening introduction to the concepts of academic integrity. The 
course's content and structure is based on elements of microlearning, an approach which is student-centred, accessible and flexible. The main premise of microlearning is that content is delivered in short segments or chunks, and in a non-linear format which allows students flexibility in selecting or revisiting sections (Paul, 2016). The incorporation of different learning tools, including videos, quizzes and activities, is intended to make learning more engaging, to help capture and maintain students' attention, and align with their habits and preferences with digital technologies. The topics that are covered in the module include: the academic community, avoiding academic misconduct, and referencing.

Upon successful completion of the course, which required an 80 per cent mark in a 20 question quiz, students received a digital badge that would be highlighted on their academic transcript. Since the trial, digital badges have been shared on students' social media profiles, like LinkedIn. This action assists students to build a portfolio of professional and personal skills and capabilities, enabling recognition by future employers.

\section{Evaluation of the trial}

The feedback from students was generally very positive, with students commenting that it was worthwhile and enjoyable. Unfortunately, there was a low participation rate for the course with only 78 of the 189 invited students completing the course, and evaluative feedback from only 31 students. Only two of the 78 who completed failed the course. Various factors contributed the low participation and feedback, including that:

- The module was not compulsory for students to complete.

- The lecture to which the Librarian was invited to speak about the module was the day before a public holiday. Students in attendance were fewer than expected.

- There were access problems associated with the learning management system, Canvas 
- There was restricted access to Canvas due to the newness of the platform (meaning that students needed to retain the link that was emailed).

- There was a problem with the communication tool within Canvas.

- There were intermittent problems with digital badge creation.

Although only a small number of students provided feedback, the small sample indicated satisfaction with the micro-credential. The respondents indicated a high level of satisfaction with, and enjoyment of, the course. There were some contradictory results, with some questions receiving low scores but given a positive comment. This suggests that students may have become confused by the agree-disagree scale being reversed for a couple of questions (possibly demonstrating a need for consistency in questionnaires).

\section{Implementation issues}

There were some technical and logistical issues surrounding the implementation, as if often the case with implementing new systems. Three groups (21CC, Library \& Student Success and ITS) were involved with the development, set-up and deployment of the academic integrity course. The consequence of three stakeholders with a vested interest meant that ownership of the product became disaggregated and communication was periodically unclear between parties. The delivery of the course to students was also encumbered with inefficiency. This included occasional absences of communication between stakeholders and an unclear delineation of responsibilities associated with the delivery of the final product. It resulted in some miscommunication, and a misunderstanding of the parameters of each stakeholder's role. As a consequence, it affected the student experience, who on occasion, were provided with ineffective responses to questions. 
On reflection, it is clear students engage with micro-credentials and gain satisfaction from completing them. Micro-credentials provide a productive and viable framework for the Library to deliver instruction and content. This project serves as an example to other libraries seeking an avenue to utilise their resources, systemise their instruction and provide training to greater numbers of students.

RMIT libraries will continue to contribute in this space, through micro-credentials that incorporate digital tools that empower digital fluency, to instruction in meta-literacies and capability building that support students' graduate attributes. Collaboration is an essential factor in the success of micro-credentials. Future collaboration will be enhanced by clearly outlined parameters relating to team responsibilities, and by cultivating partnerships within the university. These partnerships will be an important ingredient as they provide additional skills, perspectives and understanding to those provided by library staff. Digital literacies are now critical in lifelong learning and RMIT library clearly has the impetus and a pathway to evolve in this space

On a positive note, a lasting tool was produced that can now be promulgated to all students who access Canvas. This follows the current trend in embedding micro-credentials in order to facilitate greater engagement and participation. In addition, the Library and Student Success team will be able to enhance the existing module to provide a more engaged learning experience.

\section{Future development}

Academic integrity awareness was an introductory module, and further modules exploring referencing styles and perhaps using reference management software could be part of a 
scaffolded approach to skills in academic integrity. By undertaking more modules in referencing that progress to greater skill levels, students' progress could be marked throughout their learning and represented by the awarding of digital badges.

Since the trial of the Academic Integrity module there has continued development of other library credentials. The library has created modules for information literacy, collaborating online, and lifelong digital learning. These modules aim to form part of a larger digital literacy suite of products. By undertaking these micro-credentials the student can gain valuable skills which have been developed in direct alignment with RMIT's graduate attributes and are highly valued and recognised by employers.

Recent discussion has centred on how to integrate or embed credentials within online programs and whether the completion of a series of micro-credentials will provide credit towards a degree program. There is no clear pathway at this point. What is clear is that the introduction of microcredentials is changing the higher education landscape. From prompting changes to university policies and practices, to potentially lowering costs associated with degree courses and unbundling courses to enable a pick and mix approach to learning.

The current disruption in learning provides libraries with a great opportunity to rethink how libraries create content, and they may be important partners in the development, delivery, and support of aspects of the academic curriculum. 


\section{References}

Abramovich, S., Schunn, C., \& Higashi, R. (2013). Are badges useful in education?: it depends upon the type of badge and expertise of learner. Educational Technology Research, 61(2), pp. 217-232. doi:10.1007/s11423-013-9289-2

Affinito, S., Forte, M., Gardner-Athey, K., Jacobson, T., \& O'Brien, K. (2017) Metaliteracy Badging Meets Teacher Education: Collaborative Customization for Open SUNY. Paper presented at the Conference on Instruction and Technology, New York.

Ahn, J., Pellicone, A., \& Butler, B. S. (2014). Open badges for education: what are the implications at the intersection of open systems and badging? Research in Learning Technology, 22(1) doi:10.3402/rlt.v22.23563

Briggs, S. (2013). Out with the degree, in with the badge: how badges motivate learning and 7 tips to use them right. Informed, 2018(16 January) Retrieved from https://www.opencolleges.edu.au/informed/

Catalano, F., \& Doucet, K. J. (2013). Digital ‘badges' emerge as part of credentialing’s future. Institute for Credentialing Excellence, available online at www. credentialingexcellence. $\mathrm{org} / \mathrm{p} / \mathrm{cm} / \mathrm{ld} / \mathrm{fid}, 203$

Carey, K., \& Stefaniak, J. (2018). An exploration of the utility of digital badging in higher education settings. Educational Technology Research and Development, 66(5), pp. 1211-1229. doi:10.1007/s11423-018-9602-1

Cook, S., Bingham, T., Reid, S., \& Wang, L. (2015) Going massive: Learner engagement in a MOOC environment. Paper presented at the THETA: The Higher Education Technology Agenda, Gold Coast, Australia.

de Botton, A. (2015). The Desire for Credentials in an Age of Anxiety. The Chronicle of Higher Education. Retrieved from https://www.chronicle.com/article/The-Desire-for- 
Credentials-in/232971Devedžic, V., \& Jovanovic, J. (2015). Developing open badges: a comprehensive Approach. Educational Technology Research and Development, 63(4), pp. 603-620. doi:10.1007/s11423-015-9388-3

Diaz, V. (2013). Digital badges for professional development. EDUCAUSE Review. Retrieved from https://er.educause.edu/articles/2013/7/digital-badges-forprofessional-development

Dowling-Hetherington, L., \& Glowatz, M. (2017). The Usefulness of Digital Badges in Higher Education: Exploring the Students' Perspectives. Irish Journal of Academic Practice, 6(1), p 1.

ECDL Foundation. (2014). The Fallacy of the 'Digital Native': Why Young People Need to Develop their Digital Skills (Position Paper No.: E. Foundation. http://ecdl.org/media/thefallacyofthe'digitalnative'positionpaper1_1.pdf

Educause. (2018). The EDUCAUSE Microcredentials and Badges Community Group Listserv. Retrieved Date Accessed, 2018 from http://listserv.educause.edu/scripts/wa.exe?A0=DIGITALBADGES

Foli, K. J., Karagory, P., \& Kirby, K. (2016). An Exploratory Study of Undergraduate Nursing Students; Perceptions of Digital Badges. The Journal of nursing education, 55(11), p 640. doi:10.3928/01484834-20161011-06

Hickey, D. T. (2017). How Open E-Credentials Will Transform Higher Education. The Chronicle of Higher Education. Retrieved from https://www.chronicle.com/article/How-Open-E-Credentials-Will/239709

Higher Education Standards Framework (Threshold Standards) (2015).

León-Urrutia, M., Cobos, R., \& Dickens, K. MOOCs and Their Influence on Higher Education Institutions: Perspectives from the Insiders. Journal of New Approaches in Educational Research, 7(1), pp. 40-45. doi:10.7821/naer.2018.1.252 
Lewis, M. J., \& Lodge, J. M. (2016). Keep Calm and Credential on: Linking Learning, Life and Work Practices in a Complex World. In D. Ifenthaler, N. Bellin-Mularski \& D.K. Mah (Eds.), Foundation of Digital Badges and Micro-Credentials: Demonstrating and Recognizing Knowledge and Competencies (pp. 41-54). Cham: Springer International Publishing.

Lowendahl, J.-M., Thayer, T.-L., \& Morgan, G. (2016). Gartner Highlights Top 10 Strategic Technologies for Higher Education in 2017. Retrieved Date Accessed, 2018 from https://www.gartner.com/doc/3557217/top--strategic-technologies-impacting.

Lowendahl, J.-M., Thayer, T.-L., \& Morgan, G. (2016). Top 10 Strategic Technologies Impacting Higher Education in 2016. Retrieved Date Accessed, 2018 from https://www.gartner.com/doc/3186323/top--strategic-technologies-impacting.

Lowendahl , J.-M., Thayer , T.-L., Morgan , G., Yanckello, R., Resnick , M., \& Revang, M. (2018). Top 10 Strategic Technologies Impacting Higher Education in 2018. Retrieved Date Accessed, 2018 from https://www.gartner.com/doc/3844465/top-strategic-technologies-impacting.

Mcllvenny, L. (2015). Open badges: glorified award stickers or valuable learning credentials? Access, 29(1), pp. 30-40.

Mery, Y., Newby, J., \& Peng, K. (2012). Why one-shot information literacy sessions are not the future of instruction: a case for online credit courses. College \& Research Libraries, 73(4), pp. 366-377.

O'Connor, K. (2014a). MOOCs, institutional policy and change dynamics in higher education. Higher Education, 68(5), pp. 623-635. doi:http://dx.doi.org/10.1007/s10734-014-9735-Z 
O'Connor, K. (2014b). MOOCs, institutional policy and change dynamics in higher education. Higher Education: The International Journal of Higher Education and Educational Planning, 68(5), pp. 623-635. doi:10.1007/s10734-014-9735-z

Paul, A. (2016). Microlearning 101. HRMagazine, 61(4), pp. 36-40,42.

Raish, V., \& Rimland, E. (2016). Employer perceptions of critical information literacy skills and digital badges. College \& Research Libraries, 77(1), pp. 87-113.

Randall, D. L., Harrison, J. B., \& West, R. E. (2013). Giving Credit Where Credit Is Due: Designing Open Badges for a Technology Integration Course. TechTrends: Linking Research and Practice to Improve Learning, 57(6), pp. 88-95. doi:10.1007/s11528013-0706-5

RMIT. (2018). RMIT Creds. Accessed 1 October, 2018, from https://www.rmit.edu.au/creds. Rodgers, A. R., \& Puterbaugh, M. (2017). Digital badges and library instructional programs: Academic library case study. Journal of Electronic Resources Librarianship, pp. 1-9. doi:10.1080/1941126X.2017.1378542

Rutherford, E., Freund, K., \& Mewburn, I. (2015). Badging the library: Are digital badges the next innovation for library skills and training?

Shields, R., \& Chugh, R. (2017). Digital badges - rewards for learning? Education and Information Technologies, 22(4), pp. 1817-1824. doi:10.1007/s10639-016-9521-x

Wilson, B. G., Gasell, C., Ozyer, A., \& Scrogan, L. (2016). Adopting digital badges in higher education: Scoping the territory.

Wolfe, J. K., \& Andrews, D. W. (2014). The changing roles of higher education: curator, evaluator, connector and analyst. On the Horizon, 22(3), pp. 210-217. doi:10.1108/OTH-05-2014-0019 Retrieved from https://doi.org/10.1108/OTH-05$\underline{2014-0019}$ 